\title{
ВMJ Global Health Vaccinating children in high-endemic rabies regions: what are we waiting for?
}

\author{
Patrick Soentjens, ${ }^{1,2}$ Nicole Berens-Riha (D) , ${ }^{1}$ Yven Van Herrewege, \\ Pierre Van Damme, ${ }^{3}$ Emmanuel Bottieau, ${ }^{1}$ Raffaella Ravinetto (i) ${ }^{4}$
}

To cite: Soentjens $P$, Berens-Riha N, Van Herrewege $\mathrm{Y}$, et al. Vaccinating children in highendemic rabies regions: what are we waiting for?BMJ Global Health 2021;6:e004074. doi:10.1136/ bmjgh-2020-004074

Handling editor Seye Abimbola

Received 28 September 2020 Accepted 16 December 2020

\section{Check for updates}

(C) Author(s) (or their employer(s)) 2021. Re-use permitted under CC BY-NC. No commercial re-use. See rights and permissions. Published by BMJ.

${ }^{1}$ Department of Clinical Sciences, Institute of Tropical Medicine, Antwerpen, Belgium ${ }^{2}$ Centre for Infectious Diseases, MHKA, Brussel, Belgium ${ }^{3}$ Centre for the Evaluation of Vaccination, University of Antwerp, Antwerpen, Belgium ${ }^{4}$ Department of Public Health, Institute of Tropical Medicine, Antwerpen, Belgium

Correspondence to Dr Patrick Soentjens; psoentjens@itg.be

\section{INTRODUCTION}

On September 28 this year, the World Rabies Day came as a reminder that a fully preventable viral encephalitis still claims at least 59000 victims per year in over 150 countries; and particularly in rural Africa and Asia, where over $40 \%$ of individuals bitten by a suspect rabid animal are children. Sadly, these figures are probably underestimated. $^{1}$

Rabies is one of the Neglected Tropical Diseases (NTDs) announced by the WHO, that is, a diverse group of communicable diseases that particularly affect poor populations, without adequate sanitation, and living in close contact with infectious vectors. In 2013, the World Health Assembly called to intensify measures against NTDs. ${ }^{2}$ In 2015, the WHO called for action to achieve zero dog-mediated rabies deaths in humans by $2030 .{ }^{3}$ Therefore, it is crucial to enhance prevention, diagnosis, control and treatment through an integrated One Health approach. Pre-exposure prophylaxis (PrEP) with rabies vaccine plays an important role in prevention but is almost unavailable in high-endemic settings.

\section{PRE-EXPOSURE AND POST-EXPOSURE PROPHYLAXIS}

Post-exposure prophylaxis (PEP) vaccination is life-saving, if given as soon as possible after exposure. It requires several vaccination sessions and the availability of immediately acting but costly immunoglobulins (RIG). However, if individuals bitten by a rabid animal are 'primed' with PrEP, they only need as PEP a single-visit intradermal booster vaccination of $0.1 \mathrm{~mL}$ at four anatomical sites (figure 1: $1^{4} \mathrm{ID}$, schedule 2.A). Two clinical trials showed that even lower doses (single-site $0.1 \mathrm{~mL}$ or two-sites $2 \times 0.1 \mathrm{~mL}$ ) during a singlevisit booster session can activate memory cells and trigger the immune cascade in primed individuals $^{45}$ and induce an accelerated immune response compared with those who receive PEP alone. ${ }^{6}$ Additionally, primed individuals do not

\section{Summary box}

Rabies, a fully preventable viral encephalitis, still claims at least 59000 victims per year. Pre-exposure prophylaxis (PrEP) increases the probability of survival in bitten individuals but is hardly available to high-risk groups-like children-in endemic settings.

- The availability of simplified PrEP schedules and new modes of administration with a focus on specific risk groups should be seen as game-changers for PrEP feasibility in low-income and middle-income countries.

- We contend that there is a moral imperative to change the current paradigm where PrEP is available for international travellers to endemic regions but not to local individuals at risk.

- We call for a global effort to make simplified rabies PrEP available and affordable to those in need.

require RIG, which is complex to administer and mostly unavailable in low-and-middle-income countries (LMICs). ${ }^{7}$ In short, PEP without PrEP is slower-acting, time-sensitive and timeconsuming, while PrEP increases the likelihood of survival in bitten individuals, particularly in case of so-called 'category 3 exposure' (eg, transdermal bites/scratches) when RIG is unavailable. Some authors even argued that PrEP might provide sufficient protection, if exposure goes unrecognised, or when PEP is delayed, incomplete or unavailable. ${ }^{6}$

Traditionally, PrEP required three vaccinations spread over 1 month. Since 2018, the WHO recommends a simplified two-visit schedule, with two intradermal microinjections of $0.1 \mathrm{~mL}$ in each arm, on days 0 and 7 (figure 1: $2^{2}$ ID). This schedule shows a robust immune response with a good safety profile in all age groups and the potential of high adherence. ${ }^{7}$ The (2018) WHO guidelines also recommend a simplified PEP (without PrEP) schedule with six intradermal microinjections of $0.1 \mathrm{~mL}$ at days 0,3 and 7 (figure 1: $3^{2} \mathrm{ID}$, schedule 1.A) instead of the current four to five visits over 21-28 days in 
Proposed intradermal rabies schedules in high endemic setting

\begin{tabular}{|c|c|c|c|c|c|c|c|c|c|c|c|c|c|c|}
\hline & & PrEP & Volume & Day 0 & Day 7 & Day $x$ & Day $Y$ & PEP & Volume & Day 0 & Day 3 & Day 7 & Day 21 & Tot Vol \\
\hline 岌 & $\begin{array}{l}\text { 1.A. New 3-visit ID PEP } \\
\text { without HRIG }\end{array}$ & & & & & & & $3^{2}$ ID & $6 \times 0.1 \mathrm{~mL}$ & $\phi \phi$ & $\not \varnothing$ & $\phi \phi$ & & $0.6 \mathrm{~mL}$ \\
\hline ऐิ & $\begin{array}{l}\text { 1.B. Alternative 3-visit ID PEP } \\
\text { without HRIG }\end{array}$ & & & & & & & $3^{4}$ ID & $12 \times 0.1 \mathrm{~mL}$ & 8 & $\theta$ & $\&$ & & $1.2 \mathrm{~mL}$ \\
\hline 产 & $\begin{array}{l}\text { 2.A. New 2-visit ID PrEP } \\
\text { with 1-visit ID PEP }\end{array}$ & $2^{2}$ ID & $4 \times 0.1 \mathrm{~mL}$ & $\theta 0$ & $8 \phi^{\circ}$ & & & $1^{4}$ ID & $4 \times 0.1 \mathrm{~mL}$ & 8 & & & & $0.8 \mathrm{~mL}$ \\
\hline$\sum_{-1}^{\frac{n}{n}}$ & $\begin{array}{l}\text { 2.B. Alternative } 2 \text {-visit ID PrEP } \\
\text { (1 visit + } 1 \text { visit } X) \text { with } 1 \text {-visit ID PEP }\end{array}$ & $2^{2} I D$ & $4 \times 0.1 \mathrm{~mL}$ & $\phi \phi$ & & 8 & & $1^{4}$ ID & $4 \times 0.1 \mathrm{~mL}$ & 8 & & & & $0.8 \mathrm{~mL}$ \\
\hline $\begin{array}{l}\dot{0} \\
\dot{\sim} \\
\grave{\Phi}\end{array}$ & $\begin{array}{l}\text { 2.C. Possible 2-visit ID PrEP in EPI } \\
\text { (2 visits overyears:day 0-6 years) } \\
\text { with 1-visit ID PEP }\end{array}$ & $2^{2} I D$ & $4 \times 0.1 \mathrm{~mL}$ & $\$$ & & & $\phi \phi$ & $1^{4}$ ID & $4 \times 0.1 \mathrm{~mL}$ & 8 & & & & $0.8 \mathrm{~mL}$ \\
\hline 产 & $\begin{array}{l}\text { 2.D. Alternative 1-visit ID PrEP } \\
\text { with 1-visit ID PEP }\end{array}$ & $1^{2} I D$ & $2 \times 0.1 \mathrm{~mL}$ & $\$$ & & & & $1^{4}$ ID & $4 \times 0.1 \mathrm{~mL}$ & 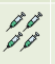 & & & & $0.6 \mathrm{~mL}$ \\
\hline 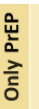 & $\begin{array}{l}\text { 3. Possible } 3 \text {-visit ID PrEP in EPI } \\
\text { ( } 3 \text { visits over vears: day } 0-6-12 \text { years) } \\
\text { in indications when } 1 \text {-visitiD PEP ID is unlikely } \\
\text { without } 1 \text {-visit ID PEP }\end{array}$ & $3^{2} I D$ & $6 \times 0.1 \mathrm{~mL}$ & $\$ 0$ & & $O D$ & $\phi \phi^{\circ}$ & $\left(1^{4} \mid D\right)$ & $(4 \times 0.1 \mathrm{~mL})$ & & & & & $0.6 \mathrm{~mL}$ \\
\hline
\end{tabular}

EPl: Expanded Programme on Child Immunization - HRIG: Human Rabies Immunoglobulines intradermal injection

Figure 1 Proposed rabies schedules for pre-exposure prophylaxis (PrEP) and post-exposure prophylaxis (PEP). ID, intradermal.

combination with RIG. However, these conventional PEP schedules are still the first recommended strategy in LMICs where PrEP does not exist.

\section{NEW PERSPECTIVES}

Given the life-saving potential of the prime-and-boostapproach, it may come as a surprise that the WHO does not recommend inclusion of rabies PrEP in expanded immunisation programmes (EPI), apparently due to doubts about costeffectiveness. ${ }^{78}$ However, is PrEP really not cost-effective? We argue that factors such as the availability of shorter schedules, new modes of administration and focus on specific risk groups could change this economic equation.

\section{Cost-effectiveness}

To the best of our knowledge, Peru and the Philippines are the only two middle-income countries that transiently provided three-visit PrEP vaccination for children in highly endemic areas. ${ }^{6}$ A study from the Philippines suggested that, assuming an annual bite incidence of $2.6 \%$, a $3{ }^{1}$ ID PrEP followed by $2^{1}$ ID PEP, is more cost-effective than a $3^{2}+1^{1}$ ID PEP plus equine RIG. ${ }^{9}$ Conversely, a modelling study from Thailand suggested cost-effectiveness only if the bite incidences were between $3 \%$ and $23 \%$ in the target population depending on the PEP given. As an actual bite incidence of $2.3 \%$ was calculated (meaning $30 \%$ of the children had been bitten by the age of 15 years), three-visit PrEP was not introduced. ${ }^{6}$ Overall, more research is needed to clarify issues of cost-effectiveness.

\section{Optimisation of resources}

Recent trials suggest that a simulated PEP booster-delayed for years-in combination with a $2^{2} \mathrm{ID}$ or $1^{2} \mathrm{ID}$ PrEP will improve the anamnestic responses after the booster. ${ }^{4}$ Hence, instead of three vaccinations in 1 week $\left(3^{2} \mathrm{ID}\right.$ PEP), the $2^{2}$ ID PrEP schedule, followed by a $1^{4}$ ID PEP in case of exposure, can improve feasibility in endemic LMICs due to longer time intervals (figure 1: schedule 1.B, 1.C, 1.D). Countries can also consider a double-dose schedule at three different visits, using the $3^{2}$ ID PEP vaccinations in a PrEP schedule, which would fit in the EPI programme: at the age of 9-12 months, and at the age of 6 and 12 years (figure 1: schedule 3 ).

In addition to improving feasibility, the simplified regimens imply better adherence and lower costs. Recent research findings suggest that even single-visit ID PrEP and PEP schedules would be safe and immunologically adequate in adults. ${ }^{7}$ A study from Thailand in children and adults suggested sufficient protection after a simulated single-visit PEP ( $\left.1^{4} \mathrm{ID}\right)$ 5years after priming. ${ }^{10}$ More research is urgently needed to evaluate single-visit schedules, particularly in vulnerable groups like children in endemic settings. ${ }^{7}$ Long-term prospective trials should assess repeated bite exposure and longer booster intervals, to understand the optimal spacing of boosters over a lifetime; evaluation of cost-effectiveness should be systematically included.

It is generally estimated that a vaccine vial containing one intramuscular dose $(0.5$ or $1.0 \mathrm{~mL})$ can be used for 4 up to 10 intradermal injections $(0.1 \mathrm{~mL}){ }^{8}$ Hence, implementation of rabies PrEP would become cheaper if vials and needles were manufactured for administration with intradermal devices, allowing to reduce the volume. ${ }^{11}$ Existing needle-free injection devices could be trialled for rabies vaccination; the results of a study that assessed such a device in 268 subjects are pending. Further data will be needed to validate these tools in rabies PrEP and PEP.

Regrettably, the Philippines discontinued the PrEP programme due to vaccine shortages, indicating a need to increase the worldwide production. ${ }^{6}$ Otherwise, there is a risk that production predominantly addresses the needs of those high-income countries that (rightly) promote PrEP in travel clinics. Investing in prequalified vaccines becomes attractive, if there is an opportunity to become suppliers for countries and for international agencies. An explicit demand from countries could result in higher production 
volumes and therefore economies of scale, facilitating preferential prices to endemic LMICs. In the long term, manufacturers could adopt new technologies such as microfacilities reducing production costs with low ecological footprints. ${ }^{12}$ Vaccines with improved thermostability, longer shelf-life and reduced packaging volume would ease transport and delivery at community level. ${ }^{7}$

\section{Raising awareness}

Sensitisation and education of those at risk, their caregivers and communities, remains critical to ensure awareness of how to avoid exposure, recognise the risk and timely access, start and complete treatment. Social science research, codesigned with the community, is needed to understand perceptions, expectations and fears and to develop locally tailored communication and sensitisation tools.

\section{Containment of the reservoir}

The importance of veterinary interventions cannot be overemphasised: dog vaccination is relatively inexpensive and it could eliminate dog-mediated rabies by 2035 , thus ending $99 \%$ of human cases. However, it needs to reach at least $60 \%-70 \%$ of the dog population and requires long-term vigilance and continued political commitment. ${ }^{7}$ In recent years, large-scale efforts were successfully launched worldwide. Ideally, dog vaccination campaigns would be linked to PrEP vaccination campaigns for humans in the next coming years.

\section{A MORAL IMPERATIVE}

Everyone has the right to promotive, preventive, curative and rehabilitative health services of quality without financial hardship. ${ }^{13}$ Yet the vaccine-preventable disease rabies kills one child about every $20 \mathrm{~min}$ - now and every day to come until elimination.

Are you still thinking of the lack of cost-effectiveness of PrEP for Thai children and of the vaccine shortage in the Philippines? Meanwhile, a monthly bite risk of $0.3 \%-1.5 \%$ in travellers to highly endemic settings resulted in a major mind-shift in favour of PrEP in this group. ${ }^{1415}$ While we agree that rabies PrEP is actively promoted in international travellers, we contend that there is a double standard: why is PrEP available for travellers to endemic regions but not to those who are born there, who share a similar or higher risk? This gap in access is morally questionable, and even more now that simplified schedules can lower costs and improve feasibility of PrEP, particularly 2'ID $+1^{4}$ ID (figure 1: 2.A-2.B-2.C).

Low-cost intradermal PrEP should be offered to all infants and children in high-endemic countries, either as part of the EPI or through mass campaigns. We call politicians, policy makers, the public and private sectors, the civil society, academia, governments and donors to join forces in this effort, as part of the collective moral obligation to promote and support universal health coverage.

Twitter Raffaella Ravinetto @RRavinetto

Contributors This commentary is based on the research experience of the authors in the field of rabies vaccines. PS and NB-R wrote the first draft, which received significant inputs from RR, EB, PVD and YVH. PS, RR and NB finalised the manuscript, which was approved by all coauthors. PS is the guarantor of this commentary and the corresponding author.

Funding The authors have not declared a specific grant for this research from any funding agency in the public, commercial or not-for-profit sectors.

Competing interests None declared.

Patient consent for publication Not required.

Provenance and peer review Not commissioned; internally peer reviewed.

Data availability statement № data are available.

Open access This is an open access article distributed in accordance with the Creative Commons Attribution Non Commercial (CC BY-NC 4.0) license, which permits others to distribute, remix, adapt, build upon this work non-commercially, and license their derivative works on different terms, provided the original work is properly cited, appropriate credit is given, any changes made indicated, and the use is non-commercial. See: http://creativecommons.org/licenses/by-nc/4.0/.

\section{ORCID iDs}

Nicole Berens-Riha http://orcid.org/0000-0003-4533-0081

Raffaella Ravinetto http://orcid.org/0000-0001-7765-2443

\section{REFERENCES}

1 WHO. Fact-sheet rabies. Available: https://www.who.int/news-room/ fact-sheets/detail/rabies [Accessed 25 Sep 2020].

2 WHO. WHA66.12. neglected tropical diseases, 2013. Available: https://www.who.int/neglected_diseases/mediacentre/WHA_66.12_ Eng.pdf

3 WHO. Ending the neglect to attain the sustainable development goals: a road map for neglected tropical diseases 2021-2030. WHO, 2020. Available: https://www.who.int/neglected_diseases/resources/ who-ucn-ntd-2020.01/en/

4 Soentjens P, De Koninck K, Tsoumanis A, et al. Comparative immunogenicity and safety trial of 2 different schedules of Singlevisit intradermal rabies postexposure vaccination. Clin Infect Dis 2019;69:797-804.

5 Soentjens P, Andries P, Aerssens A, et al. Preexposure intradermal rabies vaccination: a Noninferiority trial in healthy adults on shortening the vaccination schedule from 28 to 7 days. Clin Infect Dis 2019;68:607-14.

6 Kessels JA, Recuenco S, Navarro-Vela AM, et al. Pre-Exposure rabies prophylaxis: a systematic review. Bull World Health Organ 2017;95:210-9.

7 WHO. Rabies vaccines: WHO position paper. Weekly epidemiological record. Relevé épidémiologique hebdomadaire, 2018. Available: https://www.who.int/wer/2018/wer9316/en/ [Accessed 21 Aug 2020].

8 Hampson K, Abela-Ridder B, Bharti O, et al. Modelling to inform prophylaxis regimens to prevent human rabies. Vaccine 2019;37 Suppl 1:A166-73.

9 Deray R, Rivera C, Gripon S, et al. Protecting children from rabies with education and pre-exposure prophylaxis: a schoolbased campaign in EI NIDO, Palawan, Philippines. PLoS One 2018;13:e0189596.

10 Quiambao BP, Ambas C, Diego S, et al. Single-visit, 4-site intradermal (ID) rabies vaccination induces robust immune responses 5 years after 1 -week, 4-site ID primary post-exposure prophylaxis in the Philippines. Vaccine 2020;38:3740-6.

11 Van Mulder TJS, Verwulgen S, Beyers KCL, et al. Assessment of acceptability and usability of new delivery prototype device for intradermal vaccination in healthy subjects. Hum Vaccin Immunother 2014;10:3746-53.

12 Dohogne Colognon Y Y, Drugmand JC, Chatel A. Scale-XTM bioreactor for viral vector production. Univercells S.A. Belgium: Gosselies, 2019. https://www.univercells.com/app/uploads/2019/05/ scale-X\%E2\%84\%A2-bioreactor-for-viral-production-Adeno_SFM. pdf

13 WHO. Universal health coverage Factsheets. Available: https://www. who.int/en/news-room/fact-sheets/detail/universal-health-coverage-( uhc) [Accessed 25 Sep 2020].

14 Steffen R. Travel vaccine preventable diseases-updated logarithmic scale with monthly incidence rates. J Travel Med 2018;25:jtm/ tay046. doi:10.1093/jtm/tay046

15 Steffen R, Hamer DH. High time to prioritize rabies prevention-a new paradigm. J Travel Med 2020;27:taaa173.. 